\title{
Moralidad y felicidad en Schopenhauer y en Kant: conciertos y desacuerdos
}

\author{
Luciana Samamé \\ Doctoranda en Filosofía en la Universidad Nacional de Córdoba (Argentina) \\ E-mail: lucsamame@yahoo.com.ar
}

\begin{abstract}
RESUMEN: En este trabajo nos proponemos explorar la problemática relación entre moralidad y felicidad en las ópticas de Kant y Schopenhauer. Nos centraremos en la recepción crítica por parte de este último de ciertas concepciones kantianas concernientes a la moralidad y la felicidad, intentando evidenciar los aspectos en los que les presta su consentimiento como así también los de rechazo explícito. Para abordar esta relación crítica entre ambos filósofos, tomaremos como punto de referencia dos afirmaciones aparentemente contradictorias del mismo Schopenhauer, a saber: que Kant posee el gran mérito de haber destituido el eudemonismo de la ética, por un lado; y que esta destitución ha sido, no obstante, más aparente que real, por el otro.
\end{abstract}

PALABRAS CLAVE: Moralidad, felicidad, eudemonismo.

ABSTRACT: In this paper we will try to explore the problematic relation between morality and happiness in both Kant and Schopenhauer's view. To this respect, we will focus on the schopenhauerian reception of some Kantian accounts concerning morality and happiness, aiming to show the reasons why Schopenhauer either accept or reject them. In order to analyze this issue, we will center our attention in two apparently contradictory claims made by Schopenhauer: on the one hand, that one of the biggest merit of Kant's ethics is to have rejected eudemonism; on the other, that this rejection has been more apparent than real.

KEYWORDS: Morality, happiness, eudemonism.

\section{Introducción}

Suele considerarse que Kant rompe decisivamente con la tradición ética eudemonista, al declarar que el principio de felicidad difiere radicalmente del principio de la moralidad ${ }^{1}$. Schopenhauer, precisamente, atribuye a Kant el gran mérito de haber limpiado a la ética de todo eudemonismo. Estas son las palabras inaugurales del segundo capítulo de El fundamento de la moral. Sin embargo, esa afirmación queda matizada inmediatamente después, tras expresarse que tal depuración ha sido más aparente que real. Kant seguiría atado, en opinión de Schopenhauer, a cierta perspectiva eudemonista, ya que en su doctrina del bien supremo la cuestión de la felicidad vuelve a ser introducida en conexión con la virtud. Esta doble afirmación realizada por Schopenhauer puede resultar desconcertante. Pues por un lado, elogia al filósofo de Könnigsberg por haber logrado

\footnotetext{
${ }^{1}$ Cf. WOOD, A. "Kant versus Eudaimonism”, En: Kant's Legacy, p. 261.
} 
expulsar el eudemonismo de la ética, pero por el otro, lo critica, presuntamente, por volver a introducirlo. ¿Cómo entender ambas afirmaciones? ¿Acaso incurre Schopenhauer en una contradicción? No evidencia ser éste el caso, ya que examinadas más de cerca, sendas aseveraciones se muestran perfectamente compatibles en el marco de sus presupuestos filosóficos. Nos proponemos, entonces, reconstruir las razones por las que Schopenhauer se ve llevado tanto a elogiar como a criticar a Kant en la dirección indicada.

En el primer caso, Schopenhauer sostiene a secas que Kant ha logrado expulsar al eudemonismo de la ética. Sin embargo, no se detiene en el análisis ni tampoco en la explicitación de los argumentos mediante los cuales Kant consuma tal crítica. ¿Cómo explicar ese descuido, teniendo en cuenta la importancia que para el mismo Schopenhauer reviste la proscripción de todo rastro eudemonista de la ética? Si a esto agregamos el hecho de que aquí nos encontramos frente a uno de los escasos puntos en que aquél coincide con Kant en materia ética, ese descuido se vuelve aún más sorprendente. Aventuramos la siguiente hipótesis: Schopenhauer no reproduce ni se detiene a discutir las objeciones kantianas contra el eudemonismo, porque parece dar por sentado que han sido lo suficientemente poderosas como para seguir redundando en ello. En este contexto, no parece una tarea vana reconstruir las críticas de Kant al eudemonismo, e intentar establecer el sentido en que Schopenhauer le presta su consentimiento. Si bien los argumentos por los que el primero, a nuestro parecer, establece una distinción tajante entre moralidad y felicidad, no se reducen a un único argumento, el segundo tan sólo puede aceptar uno de ellos. Este acuerdo parcial nos ayudará a entender qué es lo que Schopenhauer quiere decir al expresar que "Kant posee el gran mérito de haber desterrado el eudemonismo". Procuraremos, en consecuencia, esclarecer el sentido en que aquél recoge la herencia de Kant en su oposición al eudemonismo. Esto nos conducirá, por su parte, a preguntarnos qué entendieron ambos filósofos por "felicidad".

Por otro lado, así como Schopenhauer adscribe la separación estricta, efectuada por Kant, entre los ámbitos de moralidad y felicidad respectivamente, termina por afirmar que este último afloja considerablemente su posición a partir de su concepción del bien supremo, en el que justamente la felicidad es incluida como uno de sus componentes esenciales. Este aspecto le resulta inadmisible a nuestro filósofo, por volver a introducir en el dominio ético un aspecto ya autorizadamente excluido del mismo, a saber: la felicidad. 
De esta manera, el autor de El mundo como voluntad y representación nos presenta un punto de vista aun más radicalizado que el del propio Kant, ya que en su opinión la felicidad no puede encontrar lugar alguno en la ética, no sólo en la teoría de la motivación moral, sino tampoco en la doctrina del bien supremo. Intentaremos alumbrar también las razones de este rechazo.

\section{Moralidad versus felicidad}

En la Crítica de la Razón Práctica Kant afirma que "lo francamente contrario al principio de la moralidad es cuando el principio de la felicidad propia se convierte en motivo determinante de la voluntad"2. Con esta aseveración, el filósofo de Könnigsberg traza una clara demarcación entre ambas esferas: cuando uno se guía por el propósito de la felicidad, se actúa en función de un principio toto genere diverso del principio moral; cuando, contrariamente, la motivación tiene por base el principio moral, se suprime ipso facto la consideración de la propia felicidad. De esta suerte, ambos principios se excluyen mutuamente. En sintonía con Kant, Schopenhauer da cuenta también de este agudo contraste:

Siempre resultó que la voluntad del hombre está dirigida solamente a su propio bienestar [Wohlsein], a lo que en su sentido más completo llamamos felicidad [Glückseligkeit]; tendencia que lo lleva por caminos muy distintos a los que quisiera la moral $^{3}$.

Por razones que intentaremos dilucidar, moralidad y felicidad se consolidan no sólo como campos independientes, sino también como esferas antagónicas. ¿Por qué constituyen ambas, a los ojos de Kant y Schopenhauer, tendencias tan contrapuestas? Creemos que parte de la respuesta reside en su peculiar forma de concebir la felicidad, pero por otro lado también, en una peculiar demanda que ambos filósofos parecen suscribir: la exigencia de separar motivos morales de no-morales, para proveer así a la ética de un sólido fundamento.

Este divorcio entre moralidad y felicidad, excede, no obstante, a Kant y Schopenhauer. Se trata, en buena medida, de una peculiaridad del pensamiento moderno. Por variadas

${ }^{3}$ SCHOPENHAUER, A. M, §2, p. 19. El subrayado es de Schopenhauer 
circunstancias de las que no podemos dar cuenta aquí, la preocupación ética en la Modernidad se modela sobre bases distintas a la de los antiguos ${ }^{4}$. La búsqueda de la felicidad, incuestionablemente aceptada por estos últimos como legítimo punto de partida de la reflexión moral ${ }^{5}$, aparece teñida en la óptica moderna de una cierta sospecha: la de implicar un enfoque egoísta. Precisamente, pensadores como Maquiavelo y Hobbes, quienes marcan decisivamente el curso posterior de la filosofía, presentan una concepción antropológica en la que sobresale el egoísmo como rasgo distintivo de su naturaleza. De allí en adelante, sostiene O. Guariglia, la filosofía moral y política convertirá en uno de sus ejes fundamentales la cuestión de cómo lograr que unos seres naturalmente egoístas lleguen a comportarse altruistamente. De este hecho se desprende una significativa consecuencia:

A partir de este momento, la pregunta de la ética filosófica por el fundamento de la moralidad, es decir, de los soportes sobre los que se sostienen las reglas morales que rigen el comportamiento entre los sujetos, queda definitivamente divorciada de la otra cuestión ética con la que estaba indisolublemente unida en la Antigüedad clásica: la cuestión del bien último, de la felicidad, en una palabra, la pregunta por la vida buena.

Veamos entonces de qué manera se hace presente tal rasgo en las concepciones éticas de Kant y Schopenhauer. Este último, como ya se ha mencionado, elogia a Kant por haber purgado a la ética de todo eudemonismo ${ }^{7}$, o en otros términos, por "haber liberado a la ética de todos los principios del mundo empírico, particularmente de toda doctrina directa o indirectamente basada en la felicidad" 8 . Schopenhauer califica de "eudemonistas" a casi todos los sistemas morales antiguos -peripatéticos, cínicos, estoicos y epicúreos-, con la sola excepción de Platón ${ }^{9}$. Los llama eudemonistas, justamente, por haber estructurado la ética en base a instrucciones para una vida feliz ${ }^{10}$. De esta manera, el filósofo de Danzig

\footnotetext{
${ }^{4}$ Cf. RAWLS, J. Lecciones sobre la historia de la filosofia moral, pp. 25-27

${ }^{5}$ Este aspecto es caracterizado por Vlastos como "el axioma eudemonista", el cual, en su opinión, se vuelve fundacional para prácticamente la mayoría de los filósofos morales de la antigüedad. De conformidad con el mismo, la eudaimonia es deseada por todos los seres humanos en cuanto fin (telos) último de todos sus actos racionales. Cf. VLASTOS, G. "Happiness and Virtue in Socrates' Moral Theory”, p. 203.

${ }^{6}$ GUARIGLIA, O. "Eudemonismo y Virtud en la Ética Antigua: Aristóteles y los Estoicos". En: Revista Diálogos 80 , p. 2.

${ }^{7}$ Cf. SCHOPENHAUER, A. M, § 3, p. 25.

${ }^{8}$ SCHOPENHAUER, A. CK, p. 627.

${ }^{9}$ Cf. SCHOPENHAUER, A. MVR II, pp. 150-157, p. 583; M, §3, pp. 25-26; CK, p. 627; HN I, 227-228 (366).

${ }^{10}$ Cf. SCHOPENHAUER, A. MVR II, p. 150.
} 
parece interpretar los sistemas antiguos en clave prudencial ${ }^{11}$, y en este sentido, exentas de un carácter propiamente moral.

Como es sabido, esta distinción entre moralidad y prudencia es claramente establecida por Kant en La fundamentación de la metafísica de las costumbres, la obra más apreciada por Schopenhauer entre sus escritos morales ${ }^{12}$. Preocupado por establecer un criterio firme de disquisición moral, Kant procura proporcionar allí una fórmula simple capaz de guiar inequívocamente a cualquier criatura racional. Sólo un ser racional -señala aquél- posee la capacidad de obrar por la representación de leyes o principios ${ }^{13}$. Ahora bien, estos principios se clasifican en dos tipos: 1) principios materiales, basados en la representación de un objeto que determina la facultad apetitiva del sujeto; 2) principios formales, cuyo fundamento yace en la mera forma de la ley. Ambos tipos de principio son definidos por Kant como imperativos, ya que su estructura se asemeja a la de un mandato, o en otros términos, a la de una fórmula para la acción. Sentado esto, se consigna que un imperativo puede mandar tanto hipotética como categóricamente. En el primer caso, el imperativo representa la necesidad práctica de una acción como medio para conseguir algo que se quiere; en el segundo, por el contrario, se representa la necesidad práctica de una acción por sí misma, es decir, sin referirla a un fin que mediante ella procura alcanzarse ${ }^{14}$. Con arreglo a ello, se sienta que sólo los imperativos categóricos son adecuados para fundar la moralidad $^{15}$.

Entre los imperativos hipotéticos, excluidos del ámbito moral, Kant distingue los imperativos de habilidad -Imperativen der Geschicklichkeit- y los imperativos de prudencia - Imperativen der Klugheit -. A los presentes propósitos, sólo interesa recalar en estos últimos, ya que se fundamentan en el fin de la felicidad. En el contexto de su discusión, Kant realiza una importante afirmación: la aspiración a la felicidad puede presuponerse "de seguro y a priori en todo hombre, porque pertenece a su esencia"16. Sin embargo, sobre ese

\footnotetext{
${ }^{11}$ Para una defensa de la interpretación de la ética antigua en clave prudencial, véase IRWIN, T. "Prudence and Morality in Greek Ethics".

${ }^{12}$ Si bien gran parte de El fundamento de la moral se dedica a la crítica pormenorizada de los presupuestos centrales de la ética kantiana expuestos en su Grundlegung, Schopenhauer no deja de reconocerle su mérito: en ella encontramos expresada, en su opinión, lo esencial de su ética en "forma sistemática, concluyente y precisa, como en ningún otro". SCHOPENHAUER, A. M, §3, p. 27

${ }_{13}$ Cf. KANT, I. Fundamentación de la metafisica de las costumbres, p. 95.

${ }^{14}$ Cf. Ibid., pp. 97-98.

${ }^{15}$ Cf. Ibid., p. 100.

${ }^{16}$ Ibíd.., p. 99.
} 
deseo de alcance universal no puede fundarse máxima moral alguna, ya que sus bases son empíricas. Este argumento es desarrollado con mayor pormenor en la Analítica de la Crítica de la Razón Práctica. Tal sección es particularmente significativa, ya que allí Kant se aplica a distinguir, en especial, la doctrina de la moralidad de la doctrina de la felicidad.

$\mathrm{Su}$ punto de partida es, precisamente, aquella distinción entre los imperativos establecida en su Fundamentación; o en otras palabras, la distinción entre máximas subjetivas y leyes prácticas. Kant intenta establecer por qué las primeras son ineptas para constituir la moralidad. Su argumento se despliega como sigue: empieza por afirmar que los principios prácticos que presuponen un objeto de la facultad apetitiva como motivo determinante de la voluntad, son empíricos en su totalidad ${ }^{17}$. A esta clase pertenecen los imperativos hipotéticos, ya que conforme se ha expresado anteriormente, apuntan a un resultado que desea conseguirse. Seguidamente, Kant asevera que cuando el sujeto se determina por la representación de un objeto al que apunta su facultad apetitiva, lo hace en virtud del placer que espera del mismo. Ahora bien:

(...) de ninguna representación de un objeto, sea ella cual fuere, puede conocerse a priori si irá unida a placer o dolor o será indiferente (...) un principio que sólo se funda en la condición subjetiva de la receptividad de un placer o dolor (que nunca puede reconocerse más que empíricamente y no puede ser valedera del mismo modo para todos los entes racionales), puede servir sin duda de máxima para el sujeto que la posee, pero no de ley para esta misma (porque carece de necesidad objetiva que deba reconocerse a priori); por lo tanto, ese principio no puede dar nunca una ley práctica ${ }^{18}$.

Kant completa esta línea de razonamiento expresando que todos los principios materiales son de la misma clase, ya que pertenecen, como tales, al principio del amor a sí mismo -Selbstliebe- o de la propia felicidad -eigene Glückseligkeit-. ${ }^{19}$ En pocas frases, el filósofo de Könnigsberg parece decir mucho. Llama la atención, ante todo, la importancia decisiva concedida al placer en cuanto fuente motivacional. De hecho, junto con el respeto -Achtung- por el deber, constituyen los únicos incentivos para la acción reconocidos por $\mathrm{Kant}^{20}$. Por otra parte, resulta bastante sugestiva la manera en que llega a conectar los

${ }_{17}$ Cf. KANT, I. Crítica de la Razón Práctica, §2, p. 32.

${ }_{18}$ Ibid., p. 33.

${ }^{19}$ Cf. Ibid., p. 33.

${ }^{20}$ En este sentido, B. Herman sostiene que Kant adscribe una teoría de la motivación un tanto restrictiva, por cuanto admite dos incentivos básicos: el incentivo moral y el incentivo del placer. Cf. HERMAN, B. 
conceptos de "placer", “felicidad” y “amor a sí mismo”. En esta dirección se encaminarán también las razones que da Schopenhauer para excluir la felicidad del reino moral.

No obstante, el argumento principal por el que Kant rechaza el principio de felicidad, tanto en la Fundamentación como en su segunda Crítica, se debe a su condicionalidad empírica. Recordemos en este punto que aquél buscaba establecer un principio de naturaleza simple, capaz de ser aprehendido por cualquier criatura racional y servir así de guía categórica para la acción. Con esto, el fundamento moral pretendía valer universalmente. Tal como había aprendido de Hume, de la experiencia no podía provenir necesidad alguna. En consecuencia, una ley universal sólo es posible sobre bases a priori, establecidas independientemente de la experiencia. Ahora bien, Kant reconoce a la felicidad como un fin humano universal, incapaz, al mismo tiempo, de fundar máxima moral alguna, por su incapacidad, precisamente, de convertirse en ley universal.

Aquél proporciona una serie de razones conexas que aquí sólo podemos presentar en forma esquemática. Supóngase que alguien, con base en el omnipresente deseo de felicidad, se determinara a actuar siguiendo, v.g., esta máxima: "para ser feliz, debo conseguir fama ante los hombres". Al parecer de Kant, dicha máxima carece de necesidad práctica, ya que su validez no puede ser establecida a priori. Se debe, en efecto, aguardar la consumación de los hechos para corroborar si efectivamente la fama reporta felicidad. No puede establecerse a priori -como se indica en el pasaje más arriba citado- si ese objeto pretendido irá unido a placer o dolor. Por otra parte, puede suceder que la persona aplicada a perseguir fama, termine por descubrir que lejos de contribuir a su felicidad, consigue el efecto contrario, al atraerse, por ejemplo, la envidia y hostilidad de los demás. En este sentido, Kant señala que el concepto de "felicidad" se trata de un concepto indeterminado, por cuanto es imposible establecer en forma fija y coherente su contenido ${ }^{21}$. Con estas argumentaciones, el autor de las tres Críticas establece la razón principal por la que el principio de felicidad no puede constituir moralidad alguna, a saber: por su condicionalidad empírica.

Llegados a este punto, cabe preguntarse: esta separación entre moralidad y felicidad, ¿es aceptada por Schopenhauer sobre la base de tal argumento? La respuesta, claramente,

“Rethinking Kant's hedonism". p. 134. Cf. también WILLIAMS, B. Ethics and the limits of Philosophy, p. 15.

${ }^{21}$ Cf. KANT, I. Fundamentación de la metafísica de las costumbres, p. 102. Cf. también Crítica del Juicio, $\S 83$, p. 298. 
es negativa. Conocidas son sus diatribas contra la idea kantiana de una razón práctica que dicta deberes incondicionados. La idea de "ley moral" le parece una presunción injustificada ${ }^{22}$. En su opinión, la tarea ética sólo puede aplicarse a la interpretación del obrar humano, de acuerdo con su esencia y contenido más íntimo. ${ }^{23}$ Lejos se encuentra su concepción, en consecuencia, de una ética prescriptiva. En este contexto, uno de los cuestionamientos que Schopenhauer dirige a Kant, apunta justamente a la ineficacia de los principios formales para motivar la acción:

(...) como para el hombre sólo tiene realidad lo empírico, o lo que se supone pudiera existir empíricamente, el estímulo moral tiene que ser, pues, un móvil empírico (...) Pues la moral ha de habérselas con la conducta real del hombre y no con los castillos de naipes a priori (...) Hemos de lamentar mucho que los conceptos puros, abstractos a priori, sin contenido real y sin ninguna clase de fundamento empírico, jamás pondrán en movimiento al menos a los hombres $(\ldots)^{24}$.

Schopenhauer rechaza enérgicamente la posibilidad de guiar la conducta sobre máximas a priori dictadas por una razón legisladora. Además del contrasentido que en su opinión involucra la noción de ley moral, o de un deber incondicionado, tales nociones poseen el inconveniente de ser ineficaces en el orden de la motivación. Una concepción de tal tipo no parece ajustarse a la realidad de la naturaleza humana, ya que a su parecer, una ley abstracta sería incapaz "de poner freno al impulso de los deseos, a la tormenta de la pasión, al poder gigantesco del egoísmo" 25 . De esta suerte, la fuerza principal que el motivo moral ha de combatir, es el egoísmo, "ese agente enemigo de la moralidad" 26 . En esta dirección, la ley moral kantiana le resulta impotente para refrenarlo. Con base en estos presupuestos, Schopenhauer no podría aceptar la crítica de Kant al principio de felicidad basada en su condicionalidad empírica y en su carencia de bases a priori, precisamente porque niega, no sólo la existencia de principios a priori en el marco de la ética, sino también la posibilidad de su eficacia práctica.

Schopenhauer sostiene, con todo, que Kant ha logrado desterrar el eudemonismo de la ética. ¿Qué quiere decir con ello? ¿Hay acaso algún argumento kantiano que le resulte

\footnotetext{
22 Schopenhauer ofrece razones pormenorizadas para el rechazo de dicha noción, en el $\S 4$ de El Fundamento de la moral.

${ }^{23}$ Cf. SCHOPENHAUER, A. MVR I, §53, p. 366.

24 SCHOPENHAUER, A. M, §6, pp. 58-59

25 SCHOPENAHUER, A. M, §6, p. 43.

26 Ibid., $\$ 14$, pp. 130-131.
} 
convincente? Creemos que sí, y es en este sentido que puede señalarse un acuerdo, el cual trataremos de precisar a continuación. Como mencionábamos anteriormente, Kant establece que todos los principios prácticos materiales son de la misma clase: pertenecen al principio del amor a sí mismo o de la propia felicidad. Con esta afirmación se desliza una inquietante sugerencia: el principio de felicidad se enraíza en el egoísmo. El siguiente pasaje parece confirmar tal cosa: Todas las inclinaciones conjuntamente (que sin duda pueden reunirse también en un sistema aceptable, y cuya satisfacción se denomina entonces la felicidad propia) constituyen el egoísmo (solipsismus) ${ }^{27}$.

Los individuos, naturalmente, tienden hacia la felicidad, pero esta inclinación natural involucra de manera esencial el amor a sí mismo, tendencia que el motivo moral debe suprimir. La moralidad, según Kant, debe oponerse al interés egoísta, a la acción en busca de recompensa ${ }^{28}$; o en términos aproximadamente equivalentes, la motivación moral debe anular la vanidad o apreciación de sí mismo ${ }^{29}$. Kant concede así que de la motivación egoísta es imposible obtener una acción con valor moral, y por ello, otra de las objeciones que parece anteponer al principio de felicidad, radica en su cuestionable procedencia: el egoísmo. De esta manera, al sostener que lo francamente opuesto al principio de la moralidad es cuando el principio de felicidad se convierte en motivo determinante de la voluntad, lo que parece tener en mente es que mientras el primero se fundamenta en la intención desinteresada, el segundo se erige en vistas del interés egoísta:

(...) el egoísta moral es el que reduce todos los fines a sí mismo (...) y que incluso, como eudemonista, pone el supremo fundamento de determinación de su voluntad (...) solamente en el provecho y en la felicidad propia (...) Por eso, todos los eudemonistas son egoístas prácticos $^{30}$.

Esta línea de razonamiento es la que ciertamente aparenta adscribir Schopenhauer. Creemos, en consecuencia, que cuando este último elogia a Kant por haber desterrado el eudemonismo, lo que quiere decir es que el filósofo de Könnigsberg ha logrado mostrar cumplidamente el abismo existente entre moralidad y felicidad, desde el punto de vista de la motivación del que uno y otro proceden. Ninguna acción engendrada en el deseo de

27 KANT, I. Crítica de la Razón Práctica, p. 111.

${ }_{28}$ Cf. KANT, I. Fundamentación de la metafísica de las costumbres, p. 113 (nota al pie).

${ }^{29}$ Cf. KANT, I. Crítica de la Razón Práctica, p. 111.

${ }^{30}$ KANT, I. Antropología en sentido pragmático, pp. 27-28. 
felicidad es capaz de sustentar significación moral, ya que su fuente no es otra que la del egoísmo $^{31}$. En última instancia, el problema moral representado por el egoísmo consiste en que, la promoción del interés propio, puede redundar en el perjuicio de los demás. A tal respecto, la perspectiva ética de Kant y Schopenhauer se modela sobre ese trasfondo de preocupaciones propias de la modernidad: cómo lograr, en palabras de Guariglia, que unos individuos naturalmente egoístas se comporten altruistamente, sin destruirse mutuamente. En este punto Kant y Schopenhauer parecen coincidir, aunque los matices, claro está, son copiosos. Fundamentalmente el contenido del motivo moral identificado por ambos -la compasión para Schopenhauer, el respeto por la ley moral para Kant-, se trata de uno de los puntos en que mayormente se manifiesta su desacuerdo. Sin embargo, parece claro el acuerdo en relación con estos dos tópicos: 1) la admisión de la existencia de motivos morales puros, de los que radicalmente difiere la motivación no-moral; 2) el relego de la felicidad al ámbito de la motivación no-moral.

\section{Concepción hedonista de felicidad}

La aspiración a la felicidad, en la medida en que deja remitirse al interés egoísta, no puede fundar moralidad alguna. Frente a esto, cabe preguntarse: ¿por qué razón Kant y Schopenhauer llegan a establecer esta vinculación entre felicidad y egoísmo? La clave de esta respuesta, creemos, reside en su concepción de felicidad, en la medida en que aparenta adoptar un sesgo hedonista. Podría afirmarse, en este sentido, que ambos filósofos se alinean en la tradición epicúrea. En opinión de A. Wood, dicha tradición resurge con fuerza en la modernidad temprana, de modo que podemos encontrar esbozada en muchos modernos una concepción hedonista de felicidad ${ }^{32}$. Tal parece ser el caso de Kant y Schopenhauer, como intentaremos evidenciar. En efecto, ambos filósofos, al aludir a la misma, lo hacen en términos de un estado satisfactorio experimentado en forma subjetiva. "Bienestar" y "placer" son términos utilizados para caracterizar ese estado que suele alcanzarse, por lo demás, tras la satisfacción del deseo. Si la felicidad es concebida en términos de un estado placentero o agradable, es claro que sólo puede hacer referencia al sujeto que lo experimenta. De esta manera, quien aspira a la felicidad, no parece aspirar a

${ }^{31}$ Cf. SCHOPENHAUER, A. MVR I, §66, p. 467.

${ }^{32}$ Cf. WOOD, A. Op. cit., pp. 261-262. 
otra cosa que a un estado subjetivo de bienestar y contento. Quien desea la felicidad, en suma, desea conseguir, fundamentalmente, algo para sí mismo. Visto de tal modo, el anhelo de felicidad se sitúa peligrosamente cerca del egoísmo o amor propio. Kant parece dar cuenta de esa vinculación en el siguiente pasaje:

(...) la conciencia de un ente racional de lo placentero de la vida que acompaña ininterrumpidamente toda su existencia -la felicidad-, y el principio de convertirla en principio determinante supremo del arbitrio, es el principio del amor a sí mismo ${ }^{33}$.

Este es uno de los importantes pasajes donde Kant nos revela su concepción de felicidad: la Glückseligkeit es referida a una condición subjetiva placentera que el sujeto pretende experimentar continuamente ${ }^{34}$. Se nos muestra así que el principio de felicidad o del amor propio, carente de significación moral, procede del anhelo por alcanzar semejante condición. Es digno de mención, además, que el filósofo de Könnigsberg concibe la Glückseligkeit en estrecha relación con nuestra naturaleza sensible, al caracterizarla como un estado enteramente dependiente de las capacidades sensitivas de los sujetos. Su concepción de felicidad atiende así, en forma sustancial, a la receptividad de éstos al placer $\mathrm{y}$ al dolor.

Schopenhauer parece hacerse eco también de una concepción análoga. El mismo reconoce, ciertamente, que los móviles fundamentales de la voluntad no son otros que los de la felicidad y el dolor ${ }^{35}$. Es decir, como el acto de la voluntad se identifica con la acción del cuerpo, cualquier influencia sobre la primera supone necesaria e inmediatamente, una influencia sobre el segundo: "en cuanto tal se denomina dolor cuando repugna a la voluntad; bienestar, placer cuando está de acuerdo con ella" ${ }^{36}$. Sentado esto, al aludir a la felicidad, Schopenhauer parece significar principalmente esta tendencia de la voluntad hacia el placer -o ausencia de dolor-. Recordemos al respecto uno de los pasajes que citábamos prácticamente al comienzo de este trabajo, donde se lo ve utilizar presuntamente

\footnotetext{
${ }^{33}$ KANT, I. Crítica de la Razón Práctica, p. 34. El subrayado es de Kant.

34 Irwin sostiene al respecto que Kant se compromete con una concepción hedonista de felicidad, aunque esto no implica la identificación llana entre placer y felicidad, por haber sugerido precisamente que esta última no equivale simplemente al primero, sino a un estado placentero ininterrumpido. Así, argumenta Irwin, mientras Kant parece querer decir que podríamos tener unos pocos segundos de placer, no llega al extremo de postular que podríamos tener unos pocos segundos de felicidad. Cf. IRWIN, T. "Kant's criticisms of eudaemonism", p. 67.

35 Cf. SCHOPENHAUER, A. M, §16, p. 139.

36 SCHOPENHAUER, A. MVR I, §18, p. 189.
} 
de manera intercambiable los conceptos de "bienestar" y "felicidad". Ahora bien, bajo tal óptica, el propósito de la felicidad parece llevarnos por caminos opuestos al requerido por la moral, al entrañar, precisamente, una perspectiva egoísta. La articulación de semejantes presupuestos puede verse reflejada en los siguientes pasajes:

El móvil principal y fundamental es, en el hombre, igual que en el animal, el egoísmo [Egoismus] es decir, el deseo de vivir y de bienestar [Wohlsein] (...) el hombre quiere incondicionalmente conservar su existencia, quiere estar totalmente libre de dolores (...) quiere tener el mayor bienestar posible y desea todo placer [Genuss] que sea capaz de disfrutar ${ }^{37}$.

Con esto, Schopenhauer indica que el móvil principal de las acciones humanas no es otro que el del placer o felicidad. Además de compartir con Kant una idea de felicidad sustentada sobre la noción de placer, nuestro filósofo coincide también con aquél en identificarla con una condición que sobreviene a la satisfacción del deseo. A partir de este presupuesto, se termina de conformar la visión hedonista comportada por ambos. Una de las afirmaciones de Kant más conocidas al respecto, la encontramos formulada en su segunda Crítica, donde expresa que la felicidad constituye ese estado en el que todo sucede conforme al deseo y voluntad del sujeto ${ }^{38}$. De manera análoga, Schopenhauer conecta también la noción de felicidad con la de satisfacción del deseo: "la sucesiva satisfacción de todo nuestro querer es lo que se piensa mediante el concepto de felicidad" 39 . Sin embargo, es preciso señalar, una vez más, la existencia de importantes contrastes entre Kant y Schopenhauer, por cuanto este último termina sosteniendo una visión extrema que al primero resultaría inaceptable ${ }^{40}$ : la idea pesimista según la cual ninguna satisfacción perdurable es posible ${ }^{41}$, que la felicidad constituye una ilusión, o aún más, un error innato ${ }^{42}$. Kant no aceptaría el presupuesto metafísico sobre el que se erige semejante creencia: el presupuesto según el cual la voluntad, esencia última de lo real, constituye un impulso insaciable comparable al tonel de las Danaides.

\footnotetext{
37 SCHOPENHAUER, A. M, §14, pp. 127-128. El subrayado nos pertenece.

38 Cf. KANT, I. Crítica de la Razón Práctica, p. 185.

39 SCHOPENHAUER, A. MVR II, p. 616. Cf. también MVR I, §52, p. 353.

${ }^{40}$ Cf. WOOD, A. op. cit., p. 281.

41 Cf. SCHOPENHAUER, A. MVR I, §38, p. 287.

${ }^{42}$ Cf. SCHOPENHAUER, A. MVR II, p. 616. Cf. también PP I, p. 331.
} 
Sobre este horizonte, Schopenhauer postula una concepción negativa de felicidad de una manera que tampoco encontramos delimitada en la filosofía de Kant. De conformidad con la misma, toda satisfacción es de naturaleza negativa, por eso, "la satisfacción o la felicidad nunca puede ser más que la liberación de un dolor"43. Si el placer o felicidad no puede experimentarse nunca en forma positiva, entonces, podría objetarse, Schopenhauer no se trata de un verdadero hedonista. Esta objeción, sin embargo, resulta poco convincente, ya que el mismo Epicuro, uno de los representantes más significativos del hedonismo, suscribe también una concepción negativa de felicidad, entendida como ausencia de dolor en el cuerpo y de turbación en el alma ${ }^{44}$. No por casualidad, al explicitar su propia visión, Schopenhauer evoca la concepción epicúrea de felicidad, con el fin de proporcionar una imagen adecuada de lo que quiere expresar mediante la suya ${ }^{45}$.

No obstante estos matices, tanto Kant como Schopenhauer, parecen concebir la Glückseligkeit, por las razones señaladas, sobre suelo hedonista. Entendida en tal dirección, esta última se muestra incapaz de engendrar moralidad alguna ${ }^{46}$. Hemos intentado mostrar hasta aquí la manera en que la posición de ambos manifiesta un acuerdo: en la separación tajante entre moralidad y felicidad, la distinción aguda entre motivos morales y no-morales, como asimismo en una determinada forma de concebir la Glückseligkeit. De no haber entendido esta última, principalmente, sobre la base del placer egoísta, probablemente su distinción entre moralidad y felicidad, no hubiera sido tan aguda ${ }^{47}$.

\section{La presunta recaída de Kant en el eudemonismo: las objeciones de Schopenhauer}

Cuando Schopenhauer atribuye a Kant el mérito de haber destituido al eudemonismo de la ética, parece indicar, según conjeturamos, el acierto en distinguir tajantemente entre moralidad y prudencia, entre la motivación desinteresada y la intención

${ }^{43}$ SCHOPENHAUER, A. MVR I, § 58, pp. 415-416.

${ }^{44}$ Cf. EPICURO. "Carta a Meneceo", en Obras, p. 63.

${ }^{45}$ Cf. SCHOPENHAUER, A. MVR I, §38, p. 288.

${ }^{46}$ En este sentido, Kant critica la posición de Epicuro por presuponer que la máxima de la felicidad coincide con la de la virtud, por confundir, en definitiva, prudencia y moralidad. Cf. KANT, I. Crítica de la Razón Práctica, p. 167.

${ }^{47}$ En opinión de Engstrom, este contraste agudo entre moralidad y felicidad se suaviza en gran medida si se considera la idea kantiana de bien supremo. El esfuerzo de Engstrom se dirige a mostrar, precisamente, que la posición kantiana no difiere en lo esencial de la posición aristotélica si revisamos cuidadosamente algunos de sus presupuestos. De esta manera, llega a sostener que la noción de "bien supremo" llega a desempeñar en la ética kantiana el mismo rol que la noción de "eudaimonia" desempeña en la aristotélica. Véase ENGSTROM, S. "Happiness and the Highest Good in Aristotle and Kant". 
egoísta a la que pertenece el deseo de felicidad. Esta última es encasillada dentro de los motivos no-morales porque, según procuramos establecer, sendos filósofos la conciben en términos hedonistas. Con todo, el acuerdo llega tan sólo hasta allí. Tras elogiar al filósofo de Könnigsberg en la dirección señalada, Schopenhauer nos sorprende con la siguiente afirmación: el destierro del eudemonismo ha sido más aparente que real, por cuanto aquél vuelve a introducirlo en la ética a partir de su doctrina del bien supremo ${ }^{48}$ ¿Por qué dirige Schopenhauer semejante acusación? Básicamente, porque considera que al incorporarse la felicidad como componente del bien supremo, vuelve a darse lugar a aquello que precisamente la moralidad debe combatir: el egoísmo. Veamos entonces en forma más detallada los eslabones de esta crítica.

Como es sabido, luego de separar estrictamente en la Analítica de la Crítica de la Razón Práctica los ámbitos de moralidad y felicidad, Kant intenta establecer luego su unión en la Dialéctica. Éste argumenta que la distinción entre el principio de felicidad y el de moralidad no significa enseguida mera oposición de ambos, ya que la razón práctica pura no quiere que se abandone la aspiración a la felicidad ${ }^{49}$. En su opinión, no podría coexistir con el querer perfecto de una criatura racional, el ser digno de la felicidad sin participar de ella $^{50}$. En la Crítica de la Razón Pura se expresa esta idea de manera contundente:

(...) cada uno tiene motivos para esperar la felicidad exactamente en la medida en que se haya hecho digno de ella (...) consiguientemente, el sistema de la moralidad va indisolublemente ligado al de la felicidad, pero sólo en la idea de la razón pura ${ }^{51}$.

Como sosteníamos anteriormente, Kant parte de la idea de que la felicidad constituye una aspiración humana universal. Sin embargo, cuando es convertida en motivo determinante de la voluntad, es incapaz de producir máximas de moralidad. La idea que parece tenerse aquí en mientes es precisamente de naturaleza contraria: una vez transformados nuestros deseos patológicos en deseos morales, convertidos ya en sujetos virtuosos, obedientes de la ley, la pretensión de felicidad se vuelve legítima.

${ }^{48}$ Cf. SCHOPENHAUER, A. M, §3, p. 26.

${ }^{49}$ Cf. KANT, I. Crítica de la Razón Práctica, pp. 138-139.

${ }^{50}$ Cf. Ibid., p. 165.

${ }^{51}$ KANT, I. Crítica de la Razón Pura, p. 589 [A 808 B 836]. 
Restablecida de este modo la relación entre moralidad y felicidad, Kant introduce la idea de bien supremo -höchstes Gut- en cuanto objeto de la razón práctica o voluntad pura, aunque precaviéndonos de no interpretarlo en cuanto motivo determinante de la misma ${ }^{52}$. Si tal fuera el caso, tendríamos heteronomía de la voluntad. Su concepto expresa más bien la idea de un fin supremo para una voluntad ya moralmente determinada ${ }^{53}$, esto es, una voluntad dirigida por el deber antes que por la inclinación. Consecuentemente, Kant concibe al bien supremo como un bien compuesto, conformado precisamente por dos elementos: virtud y felicidad. Ambos, sin embargo, comportan desigual valor: la primera supone un valor supremo e incondicionado, en tanto la segunda uno condicionado, relativo precisamente a la intención virtuosa. En este sentido, la felicidad se distribuye proporcionalmente a la moralidad.

Por su parte, como los conceptos de virtud -o moralidad- y felicidad, en opinión de Kant, son sumamente heterogéneos -äusserst ungleichartigen Begriffen-, no puede establecerse entre ellos una relación analítica con respecto al bien supremo. El enlace, por lo tanto, ha de ser sintético. Como ya había establecido en la Analítica que el principio de felicidad era inepto para producir máximas de moralidad, no estamos autorizados a pensar que la felicidad pueda ser la causa de la virtud. Sólo queda en pie la alternativa contraria, esto es, que la virtud sea causa de la felicidad, posición que Kant desea defender. Con todo, este enlace no puede establecerse empíricamente, sino con base a un mundo inteligible, ya que "pertenece totalmente a las relaciones suprasensibles de las cosas y no puede darse por las leyes del mundo de los sentidos" $\$ 54$. Kant quiere decir con ello que el comportamiento virtuoso probablemente no tenga como corolario a la felicidad en el mundo de los sentidos, pero es necesario que lo tenga en un mundo inteligible, el mundo moral precisamente. A partir de tal presupuesto, Kant se ve llevado a introducir los postulados de la inmortalidad del alma, la libertad y la existencia de Dios, postulados que garantizan, por así decir, la posibilidad práctica del bien supremo.

Hasta aquí, esquemáticamente, un atisbo de la concepción kantiana. ¿Qué es lo que Schopenhauer encuentra tan reprochable en ella? Podría señalarse, ante todo, que al filósofo de Danzig la noción de "bien supremo" le resulta, cuanto menos, cuestionable. En su

${ }^{52}$ Cf. Crítica de la Razón Práctica, p. 162.

53 Cf. Ibid., p. 172.

54 KANT, I. Ibid., p. 178. 
opinión, sólo puede existir para la voluntad un bien provisional, mas nunca un bien absoluto o supremo ${ }^{55}$. Tal parecer se relaciona con su peculiar concepción de voluntad, que demás está decir, no podría diferir más de la de Kant. Éste identifica a la voluntad con la razón práctica, mientras Schopenhauer con un impulso inconciente exento de todo propósito. En tanto la voluntad nos constituye íntimamente, somos primariamente sujetos volitivos, estando así condenados a desear y anhelar perpetuamente. En este sentido, la voluntad gira siempre en círculos viciosos y lo máximo que puede encontrar a su paso es un bien provisional, esto es, una liberación momentánea del dolor. De esta experiencia atormentada sólo puede salirse definitivamente mediante la negación de la voluntad. Sentado esto, Schopenhauer admite que este último fenómeno, en el cual culmina su ética, sólo en forma figurada podría llamarse "bien supremo" ${ }^{56}$. Supongamos entonces, hipotéticamente, que la negación de la voluntad coincide en el marco de la ética schopenhaueriana, con el bien supremo. Comparémosla ahora con la concepción kantiana. El contraste se hace visible de inmediato: en el "bien supremo" mentado por Schopenhauer no hay lugar alguno para la felicidad -entendida como satisfacción del deseo-, y hasta tampoco -podría afirmarse- para la virtud ${ }^{57}$.

No obstante, lo que al autor de Parerga y Paralipomena parece resultarle particularmente molesto, es que Kant, luego de establecer cuidadosamente la diferencia entre moralidad y felicidad, malogre su esfuerzo al intentar conciliarlas luego en su doctrina del bien supremo. La secuencia de pensamientos que Schopenhauer parece seguir es la siguiente: primeramente, Kant recusa el eudemonismo, al mostrar acabadamente que el motivo moral no sólo difiere, sino incluso se opone, al propósito de la felicidad, pero a la postre, termina por sucumbir al mismo, al reintroducir, tras su expulsión, la felicidad en la ética. No es posible compatibilizar, en la óptica schopenhaueriana, el sistema de la moralidad con el de la felicidad, ya que la segunda atenta peligrosamente contra la primera. $\mathrm{O}$ en otros términos, la incorporación de la felicidad en la ética reintroduce al temido enemigo: el egoísmo. Tal es la acusación que Schopenhauer lanza contra la concepción kantiana del bien supremo:

\footnotetext{
55 SCHOPENHAUER, A. MVR I, §65, pp. 461-462.

56 Cf. Ibid., p. 462

57 Esta afirmación es problemática, ya que el mismo Schopenhauer no es claro al respecto. Sin embargo, algunos pasajes avalan esta interpretación, pues en ocasiones confiere a las virtudes morales simplemente un rol instrumental respecto de la negación de la voluntad. Véase al respecto MVR II, cap. 48, pp. 586-588.
} 
(...) en el fondo, esto no es más que la moral en busca de la felicidad, apoyada, por tanto, en el egoísmo, ese eudemonismo que Kant había lanzado solemnemente como heterónomo, por la puerta principal de su sistema, y que, bajo el nombre de bien supremo, se ha vuelto a introducir furtivamente por la puerta trasera ${ }^{58}$.

Al parecer de Schopenhauer, Kant vuelve a implantar en su filosofía moral lo que con tanto denuedo había procurado desterrar: el interés egoísta. Uno puede preguntarse si la crítica del filósofo de Danzig está justificada. En primera instancia, su objeción no se muestra muy potente. Pues Kant es muy claro en que el bien supremo no puede ser motivo determinante de la voluntad; el único móvil moral que reconoce, es el respeto por la ley. De hecho, una de las objeciones que el autor de las tres Críticas dirige a los moralistas antiguos es que determinaban el concepto de bien supremo antes de la ley moral, cuando ninguna noción de bien puede ser establecida, en su opinión, antes que ella ${ }^{59}$. Tal procedimiento sólo puede darnos un principio de heteronomía, al suponer la determinación de la voluntad por la inclinación. Con estas y otras observaciones, Kant pretende desmarcar su posición de malentendidos: si bien es cierto que en la doctrina del bien supremo se postula como correlato de la virtud, a la felicidad, ello no significa en manera alguna que el accionar virtuoso sea interesado, que el motivo de la virtud sea la felicidad; por el contrario, el valor moral de una acción depende exclusivamente de ser ejecutado por mor de la virtud -la obediencia a la ley-. La acusación de Schopenhauer, entonces, no parece estar justificada.

Su objeción, con todo, se revela más plausible si es puesta en conexión con una de las críticas más poderosas que dirige al concepto medular de la ética kantiana, a saber: la idea de ley moral en cuanto deber incondicionado. Con esta crítica Schopenhauer saca a relucir todas sus dotes de filósofo analítico: las nociones de "ley" y "deber", son, en su opinión, ajenas a la filosofía, al ser de procedencia teológica. Separadas de tal contexto, pierden toda significación ${ }^{60}$. De esta suerte, lo que aquél pretende destacar, es que ambas nociones implican la idea de un legislador dispensador de premios y castigos; de otra manera no harían sentido. Consiguientemente, el presupuesto de un deber incondicionado comporta un sentido ficticio, dado que el concepto de "deber" sólo es significativo si se

58 SCHOPENHAUER, A. M, §4, p. 34. Cf. también CK, p. 628.

59 Cf. KANT, I. Crítica de la Razón Práctica, p. 97.

${ }^{60}$ La misma objeción es hecha por G.E.M. Anscombe, en su influyente artículo "Modern Moral Morality", de 1958. 
piensa en relación con una condición: la de la amenaza o la promesa: "Todo deber moral está, pues, condicionado necesariamente por el castigo o la recompensa; y, para hablar en los términos de Kant, es esencialmente, inevitablemente hipotético, y nunca, como él afirma, categórico"61. Este pasaje es central para el argumento que aquí pretendemos establecer: mediante el análisis del lenguaje, Schopenhauer desvela las inconsistencias del lenguaje moral empleado por Kant. Estas inconsistencias terminan por volvérsele en contra, ya que los conceptos por él empleados introducen subrepticiamente las mismas presuposiciones que se había propuesto combatir: la acción interesada, la motivación egoísta. Pues actuar por deber sólo puede significar "actuar de manera tal que uno se haga merecedor de una recompensa, en este mundo, o en otro". Y esto no es otra cosa que reducir el fundamento moral, en última instancia, a la consideración prudencial. Es en este contexto donde Schopenhauer sitúa su crítica al bien supremo. En definitivas cuentas, el mismo cree que Kant fracasa en su tentativa de proporcionar un fundamento adecuado a la moral. Mal que a este último le pese, su ética se termina asentado, según su ferviente crítico, sobre bases prudenciales, sobre el interés egoísta, que según ha mostrado ser, no es otro que el de la propia felicidad. En tal dirección, creemos, puede interpretarse la aseveración schopenhaueriana según la cual Kant no logra desprenderse del todo del eudemonismo.

\section{Referencias}

ANSCOMBE, G.E.M. “Modern Moral Philosophy”. En: Philosophy, Vol. 33, 1958, pp. $1-19$.

EPICURO. Obras. Trad. M. Jufresa. Barcelona: Altaya, 1997.

GUARIGLIA, Osvaldo. "Eudemonismo y Virtud en la Ética Antigua: Aristóteles y los Estoicos”. En: Revista Diálogos 80, 2002, pp. 1-47.

ENGSTROM, S. "Happiness and the Highest Good in Aristotle and Kant". En Engstrom, S. (et al.) (eds.), Aristotle, Kant and the Stoics: Rethinking Happiness and Duty. Cambridge: Cambridge University Press, 1996, pp. 102-138.

HERMAN, Barbara. "Rethinking Kant's hedonism”. En: Facts and Value. Essays on ethics and metaphysics for Judith Jarvis Thomson. Massachusetts Institute of Technology Press, 2001.

${ }^{61}$ SCHOPENHAUER, A. M, §4, p. 33. El subrayado es de Schopenhauer. 
IRWIN, Terence. "Prudence and Morality in Greek Ethics". En: Ethics, Vol. 105, N², 1995, pp. 284-295.

. "Kant's Criticisms of Eudaemonism". En: Engstrom, S. (et al.) (eds.) Aristotle, Kant and the Stoics: Rethinking Happiness and Duty. Cambridge: Cambridge University Press, 1996, pp. 63-101.

KANT, Inmanuel. Fundamentación de la metafísica de las costumbres. Trad. M. García Morente. Madrid: Tecnos, 2005. 2007. . Crítica de la Razón Práctica. Trad. J. Rovira Armengol. Buenos Aires: Losada, . Antropología en sentido pragmático. Trad. M. Caimi. Buenos Aires: Losada, 2009.

. Crítica de la Razón Pura. Trad. Pedro Ribas. Madrid: Gredos, 2010.

RAWLS, John. Lecciones sobre la historia de la filosofía moral. Barcelona: Paidós, 2001.

SCHOPENHAUER, Arthur. El Fundamento de la Moral. Trad. Vicente Romano García. Buenos Aires: Aguilar, 1960.

. Escritos Inéditos de Juventud 1808-1818. Sentencias y Aforismos II. Trad. y Selec. Roberto Aramayo. Valencia: Pre-textos, 1999.

. El Mundo como Voluntad y Representación. Vol. 1. Trad. Roberto Aramayo. Madrid: FCE, 2005.

. El Mundo como Voluntad y Representación. Vol. II. Trad. Roberto Aramayo. Madrid: FCE, 2005. . Parerga y Paralipomena I. Trad. P. Lopez de Santamaría. Madrid: Trotta, 2006.

VLASTOS, Gregory. "Happiness and Virtue in Socrates' Moral Theory". En: Socrates. Ironist and Moral Philosopher. Cambridge, Cambridge University Press, 1991.

WILLIAMS, Bernard. Ethics and the Limits of Philosophy. Abingdon: Routledge, 2006.

WOOD, Allen. “Kant versus Eudaimonism”. En: Kant's Legacy: Essays in honor of Lewis White Beck. Rochester: University of Rochester Press, 2001, pp. 261-281. 
Revista Voluntas: estudos sobre Schopenhauer - 2º semestre 2011 - Vol. 2 - № 2 - ISSN: 2179-3786 - pp. 140-159.

Approved: 02/01/12 